\title{
Regional trends in births during the COVID-19 crisis in France, Germany, Italy, and Spain
}

Bruno Arpino $^{1}$, Francesca Luppi ${ }^{2 *}$, Alessandro Rosina ${ }^{2}$

${ }^{1}$ DISIA, University of Florence, 50134, Florence, Italy

${ }^{2}$ Department of Statistical Sciences, Università Cattolica del Sacro Cuore, 20123, Milan, Italy

Keywords: Fertility, COVID-19, regions, birth rates, Europe.

\begin{abstract}
Early evidence shows mixed effects of the COVID-19 pandemic on births in Europe. This study examines changes in births at the regional level in the four European countries that have been affected by the pandemic earlier and to a larger extent. It is also investigated the association between birth changes and some labour market characteristics, the pandemic impact in terms of COVID-deaths, and the share of population at risk of poverty. Results show considerable within-country heterogeneity in birth changes after the pandemic and that higher share of poverty, worse labour market performance, and higher excess mortality are associated with births decline.
\end{abstract}

\section{Introduction}

A negative impact of the COVID-19 pandemic on fertility has been predicted in high income countries (Aassve et al. 2020), mainly due to the economic effects of the pandemic (Luppi et al. 2020, Guetto et al. 2020).

Early evidence on Europe shows mixed effects of the COVID-19 pandemic. Aassve and colleagues (2021) find a significant decline in the crude birth rates from November 2020 until February 2021 in Southern Europe, Austria, and Belgium. No significant effect is found, instead, in the Nordic countries, France and Germany. Similar findings are shown also by Sobotka and colleagues (2020).

This evidence is consistent with survey data analysed by Luppi et al. (2020) who report a considerably higher proportion of abandoned fertility plans in the 2020 in Italy and Spain, compared to France, 
UK, and Germany. The authors suggest that the COVID-related economic recession might especially burden the young and female components of the labour force, hence threatening their fertility plans.

The present study explores observed monthly crude fertility rate (CFR) trends at the regional level in France (FR), Germany (DE), Italy (IT) and Spain (ES) and their associations with some characteristics of the labour market, the share of population at risk of poverty and social exclusion, and the pandemic impact in terms of deaths due to COVID-19 (i.e., excess mortality). Regional-level analyses allow to consider contextual characteristics by isolating shared and country-specific features (Beaujouan 2021).

Because the COVID-19 pandemic resulted into both a health and an economic crisis, its effects on births might indirectly pass at least through two channels. The first concerns the psychological shock caused by the spread of the Coronavirus and COVID-related deaths and by the indefinite suspension of the everyday life due to the adoption of drastic containment measures (e.g., the lockdown). The second relates to the expected and actual economic consequences of the anti-COVID restrictive measures.

The countries on which we focus are among those who have been more strongly hit by the pandemic (highest relative number of cases) in its early phase in Europe1 (between February and April 2020), show heterogenous trends in births during the pandemic, and represent the largest part of the European population. UK is not examined because of lack of data on monthly births.

\section{Data and Methods}

Data. We used monthly data on the number of births at minimum available regional level of aggregation (NUTS-2 for Italy and Spain; NUTS-1 for France and Germany) from November 2019 to May $2021^{2}$. CFR is calculated by dividing the number of births by the average female population aged 15-49 in the region in the same year (per 1000). Excess mortality has been calculated as the proportion of exceeding deaths in March-June 2020 compared to the average number of deaths in the

\footnotetext{
${ }^{1}$ Data available at: https://qap.ecdc.europa.eu/public/extensions/COVID-19/COVID-19.html\#global-overview-tab.

${ }^{2}$ Data on births are from: INSEE (France) https://www.insee.fr/fr/statistiques/5400320? sommaire=5348638\#graphiquefigure3_radio1; DESTATIS (Germany) https:/www-genesis.destatis.de/genesis//online?operation=table \&code=12612$0101 \&$ bypass $=$ true $\&$ levelindex $=1 \&$ levelid=1625750906349\#abreadcrumb; ISTAT (Italy)

http://demo.istat.it/bilmens/index.php?anno=2021\&lingua=ita; INE (Spain) https://www.ine.es/dynt3/inebase/en/index.htm?padre=7765\&capsel=7765. Because of lack of data for the 2019, the birth series for France starts in January 2020. Data on the total female population are from Eurostat: https://ec.europa.eu/eurostat/databrowser/view/DEMO_R_PJANGROUP_custom_1359026/default/table
} 
same months from the 2016 to the 2019 (per cent) $^{3}$. Other variables included in the analyses are: youth unemployment rates for people aged 25-34 in 2019 and 20204; female employment rates for women aged 25-34 in 2019 and 20205; the proportion of people at risk of poverty and social exclusion in 2019, which indicator corresponds to the sum of persons who are at risk of poverty, or severely materially deprived, or living in households with very low work intensity ${ }^{6}$; the change in the number of working hours of employed people (aged 20-64) in 2020, calculated as percentage points change compared with $2019^{7}$; the annual change in the share of people (aged 20-64) usually working from home in 2020, calculated as percentage points change compared with $2019^{8}$.

Models. We plotted CFR by region over the period of observation (Fig.1), together with quadratic trends obtained by regressing CFR on Time and Time squared, separately before and since November 2020. Time represents the month of observation. Next, we estimated linear regression models separately for each region. We included a dummy variable representing the during pandemic period vs the pre-pandemic period as the independent variable. Figure 2 plots the coefficients estimated from these regressions, representing the changes in CFR from pre-pandemic to during the pandemic period. In Fig. 2 we did not show confidence intervals because due to the limited number of observations the intervals mostly overlapped. Finally, to assess the association between specific regional features and changes in CFR, we estimated meta-regressions where the dependent variable is represented by the changes in CFR estimated from the linear regression in Fig.2. We estimated 7 models including excess mortality as independent variable, together with one of the other 7 selected economic indicators (listed in Table 1) at the time to avoid collinearity. All models control for country fixed effects. Meta-regressions allow accounting for the fact that CFR changes are estimated by weighting

\footnotetext{
${ }^{3}$ Data on deaths are from Eurostat: https://ec.europa.eu/eurostat/databrowser/view/DEMO_R_MWK2_TS_custom_1166160/default/t $\underline{\text { able }}$

${ }^{4}$ Retrieved from Eurostat: https://ec.europa.eu/eurostat/databrowser/view/LFST R LFU3RT custom 1145384/default/table ${ }^{5}$ Retrieved from Eurostat: https://ec.europa.eu/eurostat/databrowser/view/LFST_R_LFE2EMPRT custom_1364493/default/t $\underline{\text { able }}$

${ }^{6}$ Retrieved from Eurostat: https://ec.europa.eu/eurostat/databrowser/view/ILC PEPS11\$DEFAULTVIEW/default/table

${ }^{7}$ Retrieved from Eurostat: https://ec.europa.eu/eurostat/statisticsexplained/images/1/1d/04_Labour_market_RYB2021.xlsx

${ }^{8}$ Retrieved from Eurostat: https://ec.europa.eu/eurostat/statisticsexplained/images/1/1d/04_Labour_market_RYB2021.xlsx
} 
appropriately the observations using the standard errors obtained from the linear models represented in Fig.2.

\section{Results}

Figure 1 describes, for each region separately, the observed monthly crude fertility rate (CFR) (blue curve) and the fitted quadratic trends before (red curve) and after November 2020 (green curve); the red vertical line represents November 2020. Regions are in ascending order of the mean change in CFR after the pandemic (November 2020-May 2021) as compared to before it (November 2019-May 2020). German regions tend to cluster among those with the lowest variations in CFR, while Spanish and Italian regions tend to prevail among those with the highest drops in CFR. However, strong within-country variability is observed. Some Southern European regions are present also in the upper part of the plot, while some French and German regions appear also in the lower part.

Figure 2 reports the coefficients from a linear regression model with CFR as dependent variable, and a time dummy variable as independent variable, contrasting the pandemic period (November 2020May 2021) with the same months of the pre-pandemic period (November 2019-May 2020). The aim is to provide - at a glance - a comparison among regional changes in CFRs potentially due to the pandemic. Results confirm heterogeneity between regions and within countries in the changes in CFR. All Spanish and almost all Italian regions report a decline in CFR (except for Valle d'Aosta, Abruzzo and Trentino Alto Adige in Italy). Similarly, in France most of the regions show a decline, even if usually lower than those observed in the two Mediterranean countries. In Germany, CFRs changes are negative only in few regions.

Further, we investigate the potential role of some contextual characteristics in shaping changes in regional CFRs across the pandemic: excess mortality; labour market features (youth unemployment rate, female employment rate, the share of teleworkers and the change in working hours); and the proportion of the population at risk of poverty and social exclusion ${ }^{9}$ (see Supplementary Information for the full dataset and sources of data), as an indicator of economic regional performance.

Results from eight meta-regressions are reported in Table 1. CFRs declined more in regions where youth unemployment is higher, either measured before (Model 1) or during the pandemic (Model 2), where female employment is lower (Model 3 and Model 4), and where the proportion of population

\footnotetext{
${ }^{9}$ On the risk of poverty, data are not available for French regions
} 
at risk of poverty is higher (Model 5). Excess mortality is statistically significantly and negatively associated with CFRs only in Model 1, although its coefficient remains stable in all models. Changes in the number of working hours and in the amount of people doing teleworking in 2020 are not statistically significantly associated with changes in CFRs (Model 6 and Model 7).

\section{Discussion}

While previous studies found a between-country variability in the birth trends as a possible consequence of the COVID-19 pandemic, we demonstrate a substantial within-country heterogeneity. According to our estimates, compared to the pre-pandemic period, since November 2020 about 35 babies per 100.000 women were not born in Comunidad de Madrid (ES), 31 in Murcia (ES), 29 in Castilla La Mancha (ES), 25 in Calabria (IT), 23 in Molise (IT), 20 in Bremen (DE), 19 in Ile de France (FR). On the other side of the continuum, in Sachsen (DE) 17 additional babies were born in the same period compared to the pre-pandemic one, 16 in Saarland (DE), 5 in Valle d'Aosta (IT). Although we do not know what would have happened in the absence of the pandemic, our findings show that CFRs declined the most among regions with higher share of poverty and worse labour market characteristics, and higher excess mortality.

Even though our results at the country level are consistent with those from other studies (Aassve et al. 2021, Sobotka et al. 2020), due to the lack of longer series of pre-pandemic and post-pandemic monthly data on births at the regional level, we do not attribute a causal meaning to our estimates. Despite their descriptive nature, our findings stimulate further investigations with longer series of macro-level data or with micro-level data to assess to what extent the impact of the COVID-19 pandemic on fertility has been channelled by the features of the local context, and in particular, by local labour market conditions.

\section{References}

1. Aassve, A., Cavalli, N., Mencarini, L., Plach, S., \& Bacci, M. L. (2020). The COVID-19 pandemic and human fertility. Science, 369(6502), 370-371.

2. Aassve, A., Cavalli, N., Mencarini, L., Plach, S., \& Sanders, S. (2021). Early assessment of the relationship between the COVID-19 pandemic and births in high-income countries. Proceedings of the National Academy of Sciences, 118(36). 
3. Beaujouan, E. (2021). Covid-19 Global Demographic Research Needs? Replacing Speculative Commentaries with Robust Cross-national Comparisons. In Covid-19 and the Global Demographic Research Agenda, edited by Landis MacKellar and Rachel Friedman, 8-14. New York: Population Council, 2021.

4. Luppi, F., Arpino, B., \& Rosina, A. (2020). The impact of COVID-19 on fertility plans in Italy, Germany, France, Spain, and the United Kingdom. Demographic Research, 43, 13991412.

5. Guetto, R., Bazzani, G., \& Vignoli, D. (2020). Narratives of the future shape fertility in uncertain times. Evidence from the COVID-19 pandemic (No. 2020_11). Università degli Studi di Firenze, Dipartimento di Statistica, Informatica, Applicazioni" G. Parenti". Available at https://local.disia.unifi.it/wp_disia/2020/wp_disia_2020_11.pdf

6. Sobotka, T., Jasilioniene, A., Galarza, A. A., Zeman, K., Nemeth, L., \& Jdanov, D. (2021). Baby bust in the wake of the COVID-19 pandemic? First results from the new STFF data series. arXiv [Preprint] Available at https://doi.org/10.31235/osf.io/mvy62 (accessed 4 November 2021) 
Figure 1. Observed variations in the monthly CFRs (blue line) and fitted quadratic trends (red and green line) at the regional level. The vertical red line corresponds to November 2020.

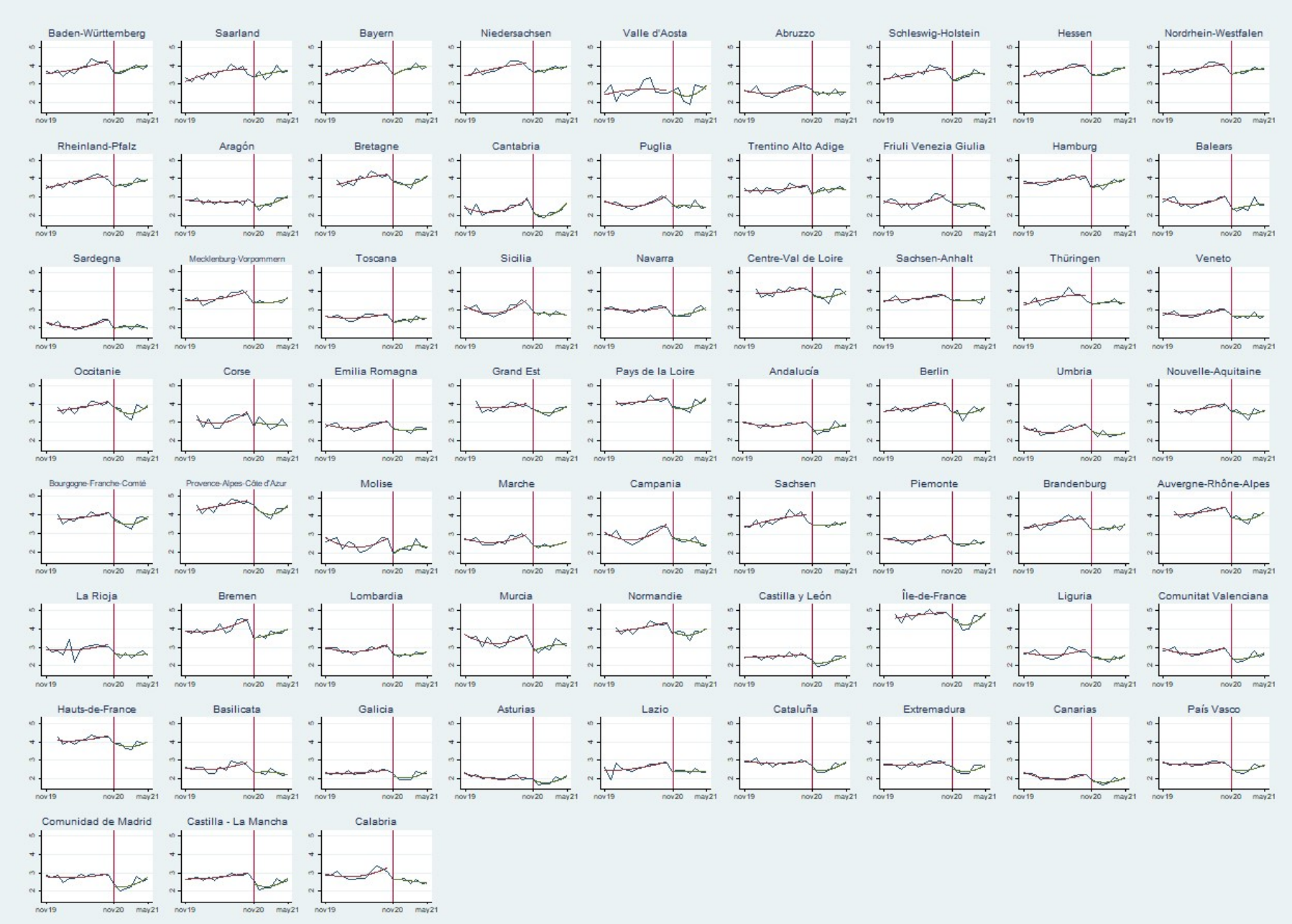


Figure 2. Changes in the monthly CFR (since vs before November 2020) at the regional level (coefficients from linear regression models).
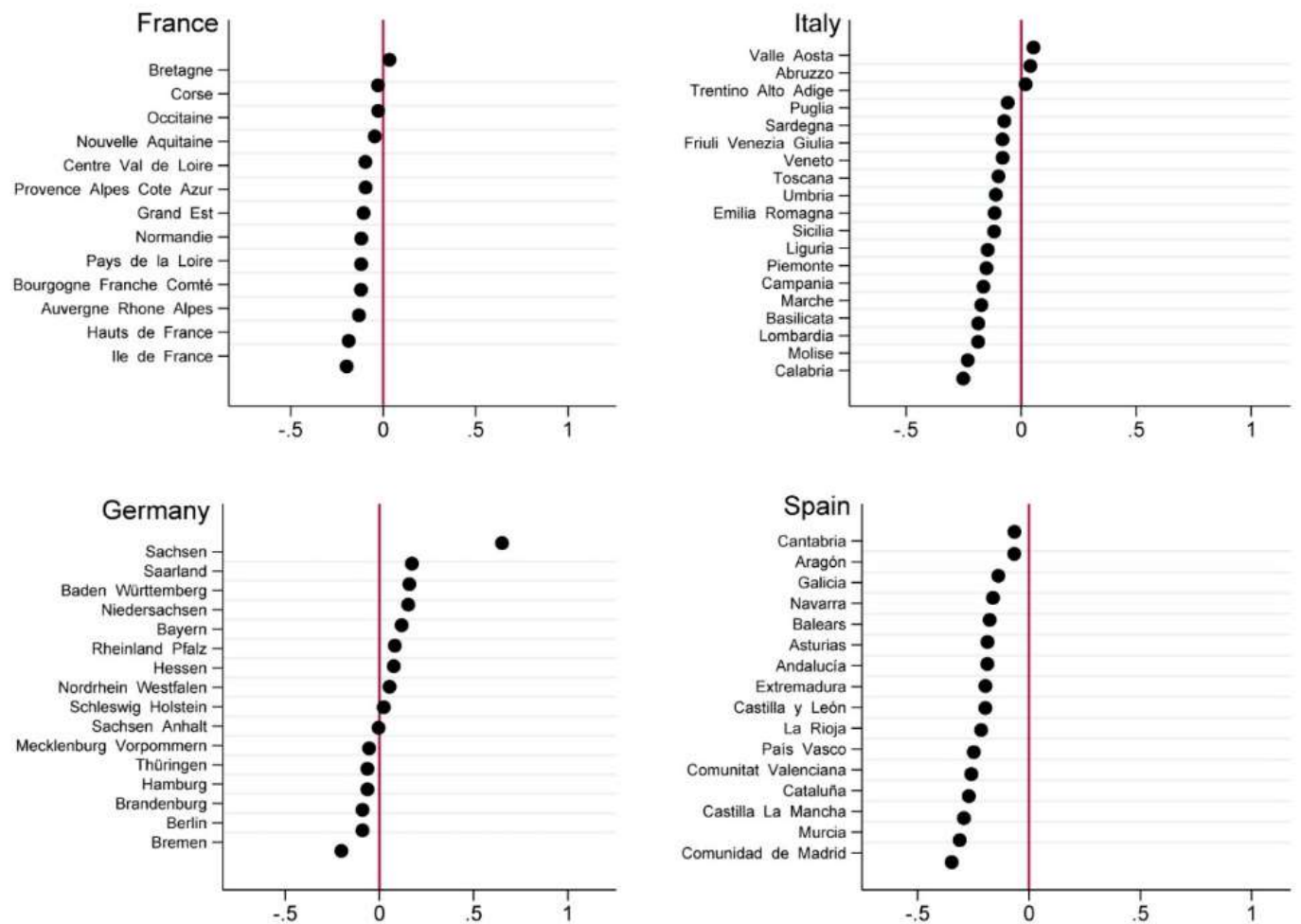
Table 1. Meta-regression models of CFRs variations as function of excess mortality, regional labour market features and risk of poverty

\begin{tabular}{lcc}
\hline & CFRs & \\
\hline & coeff. & p-value \\
\hline Model 1 & & \\
Excess mortality & -0.001 & 0.066 \\
Youth unemployment (25-34 y.o.) 2019 & -0.006 & 0.028 \\
\hline
\end{tabular}

\section{Model 2}

Excess mortality

$\begin{array}{ll}-0.001 & 0.110\end{array}$

Youth unemployment (25-34 y.o.) 2020

$-0.006 \quad 0.056$

\section{Model 3}

Excess mortality

Female employment (25-34 y.o.) 2019

$-0.001 \quad 0.114$

\section{Model 4}

Excess mortality

Female employment (25-34 y.o.) 2020

$\begin{array}{ll}-0.001 & 0.106 \\ 0.003 & 0.067\end{array}$

\section{Model 5}

Excess mortality

$\begin{array}{ll}-0.001 & 0.150\end{array}$

People at risk of poverty and social exclusion 2019

$-0.004 \quad 0.052$

\section{Model 6}

Excess mortality

Change in number of working hours 2019-2020

$\begin{array}{ll}-0.001 & 0.288 \\ 0.004 & 0.263\end{array}$

\section{Model 7}

Excess mortality

$\begin{array}{ll}-0.001 & 0.247\end{array}$

Change in proportion of people doing teleworking 2019-2020

$0.005 \quad 0.351$

Controls (estimates from Model 1) ${ }^{a}$

Countries (ref. Germany):

Italy

$-0.147 \quad 0.000$

France

$-0.121 \quad 0.007$

Spain

$-0.239 \quad 0.000$

Notes: a. Estimates of the coefficients for the dummy variables from the other models were very similar. 